\title{
Spin states, bonding and magnetism in mixed valence iron(0)-iron(II) complexes
}

\author{
Daniel Kim, ${ }^{\dagger}$ Daniel W. N. Wilson, ${ }^{\dagger}$ Majed S. Fataftah, Brandon Q. Mercado and Patrick L. \\ Holland* \\ Department of Chemistry, Yale University, 225 Prospect Street, New Haven, Connecticut. \\ * E-mail: patrick.holland@yale.edu
}

${ }^{\dagger}$ These authors contributed equally, and should be considered co-first authors.

\begin{abstract}
We report the synthesis of two complexes featuring unsupported Fe-Fe bonds, $\mathrm{L}^{\mathrm{x}} \mathrm{Fe}-\mathrm{Fp} \quad\left(\mathrm{L}^{\mathrm{a}}=\right.$ 3-methyl-2,4-bis(2,6-dimethylphenylimido)pentyl, $\mathrm{L}^{\mathrm{b}}=$ 1,3-bis(2,4,6trimethylphenylimido)propyl; $\left.\mathrm{Fp}=\mathrm{Fe}(\mathrm{CO})_{2} \mathrm{Cp}\right)$. Mössbauer spectroscopy, SQUID magnetometry and computational analysis indicate that the most accurate electronic structure description is $\mathrm{LFe}^{\mathrm{II}}-\mathrm{Fe}^{\mathrm{O}}(\mathrm{CO})_{2} \mathrm{Cp}$, in which the $\mathrm{Fe}(\mathrm{CO})_{2} \mathrm{Cp}$ is low spin iron $(0)$ and acts as a Lewis base toward the high spin iron(II) of the LFe fragment which is a Lewis acid. In both compounds, the three-coordinate high-spin iron(II) site has large zero-field splitting (zfs), up to $D=-50 \mathrm{~cm}^{-1}$.
\end{abstract}

Keywords: Metal-metal bond, iron complex, magnetism, spin state

\section{Introduction}

Molecules featuring metal-metal $(\mathrm{M}-\mathrm{M})$ bonds first received significant attention with regard to the nature of the intermetallic bonding, ${ }^{[1-6]}$ but have now grown into a vigorous field including applications as catalysts for organic transformations. ${ }^{[7,8]}$ There are also a number of cofactors of metalloenzymes that have two metals within range of forming $\mathrm{M}-\mathrm{M}$ bonds $(<3$ $\AA$ ). For example, in hydrogenases, reduction of the cofactor places electrons into a $\mathrm{M}-\mathrm{M}^{\prime}$ bond $\left(\mathrm{M}=\mathrm{Fe}, \mathrm{M}^{\prime}=\mathrm{Fe}\right.$ or $\left.\mathrm{Ni}\right)$ that enables it to oxidatively insert the $\mathrm{H}_{2}$ substrate. ${ }^{[9]}$ In the FeMoco of molybdenum-dependent nitrogenase, the close metal-metal distances have fuelled 
speculation that $\mathrm{M}-\mathrm{M}$ bonds could store electrons during the catalytic reduction of nitrogen. ${ }^{[10,11]}$ However, for iron systems (nitrogenases and others), there are typically bridging ligands, the effects of which are difficult to deconvolute from the $\mathrm{M}-\mathrm{M}$ interaction itself. Complexes featuring an unsupported $\mathrm{Fe}-\mathrm{Fe}$ bond can give more direct insight into metal-metal bonding, but they are rare and typically feature low-spin $\mathrm{Fe}^{0 / I}$ centers stabilized by $\pi$-acidic carbonyl ligands, for example the $\left[\mathrm{Fe}_{2}(\mathrm{CO})_{8}\right]^{2-}$ dianion (Figure $\left.1 ; \mathbf{A}\right) \cdot{ }^{[12-16]}$

To our knowledge, there are only two examples of isolated complexes with unsupported $\mathrm{Fe}-\mathrm{Fe}$ bonds that are not diamagnetic. The first is a homoleptic Fe-Fe complex supported by macrocyclic [14]-1,3,8,10-tetraeneN 4 (tim) ligands at each $\mathrm{Fe}$ site (B). ${ }^{[17]}$ Electron delocalization between the identical iron sites gave rise to an intermediate-spin $S=1$ ground state. In contrast, the complex $\mathrm{Ar}{ }^{\prime} \mathrm{Fe}-\mathrm{Fp}\left(\mathrm{Ar}^{\prime}=\mathrm{C}_{6} \mathrm{H}_{3}-2,6-\left(\mathrm{C}_{6} \mathrm{H}_{3}-2,6-{ }^{i} \mathrm{Pr}_{2}\right)_{2}, \mathrm{Fp}=\mathrm{FeCp}(\mathrm{CO})_{2}\right)$ (C) had two different iron sites: a slightly bent, two-coordinate high-spin iron(II) site and a low-spin iron(0) site in Fp. ${ }^{[18]}$ The sterically demanding terphenyl ligand protects a twocoordinate, high-spin Fe site. Despite a short Fe-Fe bond (2.393(1) Å), DFT calculations indicated that the metal-metal bond order was only 0.36 , and it was classified as a dative bond from the Fp group to the two-coordinate iron. Inspired by this apparent "metalloligand" on a low-coordinate iron site, we report the synthesis and characterization of two complexes featuring unsupported Fe-Fe bonds. These show exceptionally large zero-field splitting which is sensitive to the details of the supporting bidentate ligand. Further, we use Mössbauer measurements to quantify the Fp "metalloligand" on a scale with more conventional ligands, giving insight for future design of multimetallic complexes. 


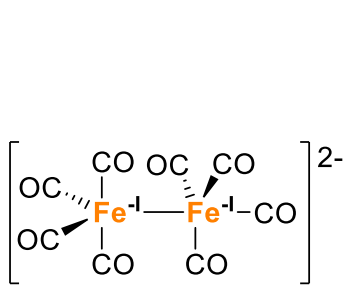

A

Fe-Fe (Â): $\quad 2.787(2)$

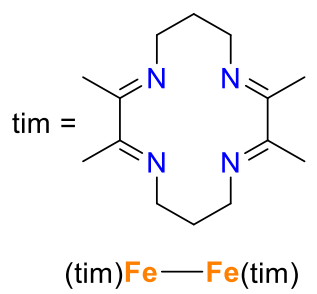

B

2.687(1)



C

$2.393(1)$

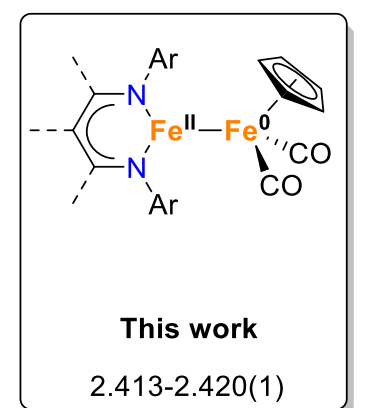

$2.413-2.420(1)$

Figure 1. Selected examples of complexes featuring unsupported Fe-Fe bonds. The metal oxidation states for $\boldsymbol{B}$ are ambiguous due to the non-innocence of the ligand.

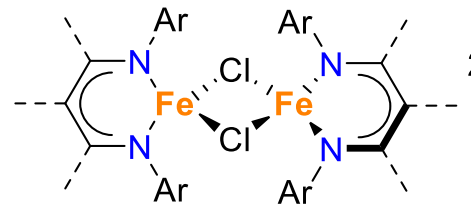<smiles>CCOC(=O)C(=O)OCC</smiles>

1a $\mathrm{Ar}=$ Mes, $\mathrm{L} \alpha=\beta=\mathrm{Me}$ 1b $A r=X y l, L \alpha=\beta=H$

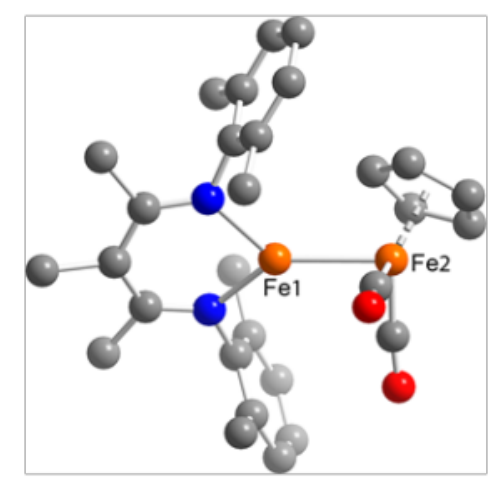

Figure 2. Left: Synthesis of $\mathbf{1} \boldsymbol{a}$ and $\mathbf{1 b}$. Right: Solid state structure of $\mathbf{1} \boldsymbol{a}$ (see S.I. for $\mathbf{1 b}$ ). Mes = 2,4,6-trimethylphenyl, Xyl = 2,6-dimethylphenyl.

Treatment of $[\mathrm{LFeCl}]_{2}\left(\mathrm{~L}^{\mathrm{a}}=3\right.$-methyl-2,4-bis(2,6-dimethylphenylimido)pentyl (1a); $\mathrm{L}^{\mathrm{b}}=$ 1,3-bis(2,4,6-trimethylphenylimido)propyl (1b)) with 0.5 molar equivalents of $\mathrm{K}\left[\mathrm{FeCp}(\mathrm{CO})_{2}\right]$ in diethyl ether affords complexes 1a or 1b, depending on the choice of ligand L. Many of the properties of $\mathbf{1 a}$ and $\mathbf{1 b}$ are closely analogous. The ${ }^{1} \mathrm{H}$ NMR spectra of both complexes exhibit paramagnetically shifted resonances. In both cases, the number of proton environments with the expected integrations indicate equivalence between the ortho- $\mathrm{CH}_{3}$ environments and free rotation about the $\mathrm{Fe}-\mathrm{Fe}$ bonds.

Dark red crystals suitable for X-ray diffraction studies were grown by cooling saturated ether/hexane solutions, and were isolated in good yields $(62 \%$ and $88 \%$ for $\mathbf{1 a}$ and $\mathbf{1 b}$, respectively). The solid-state structures confirmed the presence of short, unsupported $\mathrm{Fe}-\mathrm{Fe}$ bonds of 2.4199(3) (1a) and 2.4127(2) $\AA$ (1b). These bond lengths are significantly shorter than that of $\left[\mathrm{Fe}_{2}(\mathrm{CO})_{8}\right]\left[\mathrm{Na}(18 \text {-crown-6) }]_{2}(2.787(2) \AA)\right.$ and $\left[\{\mathrm{Fe}(\mathrm{tim})\}_{2}\right](2.6869(6) \AA)$, and are 
comparable to the $\mathrm{Fe}-\mathrm{Fe}$ distance in $\mathrm{Ar}^{\prime} \mathrm{FeFe}(\mathrm{CO})_{2} \mathrm{Cp}(2.3931(8) \AA) .{ }^{[17-19]}$ The $\mathrm{Fe}-\mathrm{Fe}$ bond in both complexes have a formal shortness ratio of 1.03-1.04 (sum of single-bond covalent radii $\mathrm{Fe}-\mathrm{Fe}=2.33 \AA),{ }^{[20]}$ and are significantly shorter than the Fe-Fe distance in metallic iron $(2.48$ $\AA$ ). ${ }^{[5]}$ The short distance arises from the low coordination number of one iron atom in these complexes. Comparison of the solid state parameters of $\mathbf{1 a}$ and $\mathbf{1 b}$ shows that removal of the methyl groups on the ligand backbone leads to an increase in the N-Fe-N bond angle from $91.2(1)^{\circ}(\mathbf{1 a})$ to $95.1(1)^{\circ}(\mathbf{1 b})$. This is accompanied by a small decrease in the average N-Fe1Fe2 angles (1a: $\left.134.2(1)^{\circ} ; \mathbf{1 b}: 132.4(1)^{\circ}\right)$. Both $\mathbf{1 a}$ and $\mathbf{1 b}$ are planar about the three coordinate Fe atom (sum of bond angles: 1a; $\left.359.6(1)^{\circ} . \mathbf{1 b} ; 360.0(1)^{\circ}\right)$. Coordination leads to distortion of the Fp fragment as well, which can be quantified through the sum of the bond angles, treating the centroid of the $\mathrm{Cp}$ as one bond $\left(\mathbf{1 a} ; 354.7^{\circ} ; \mathbf{1 b} ; 354.1^{\circ}\right)$, which pyramidalizes relative to the parent $\mathrm{K}[\mathrm{Fp}]$ anion, which is planar $\left(360.0^{\circ}\right) .{ }^{[21]}$

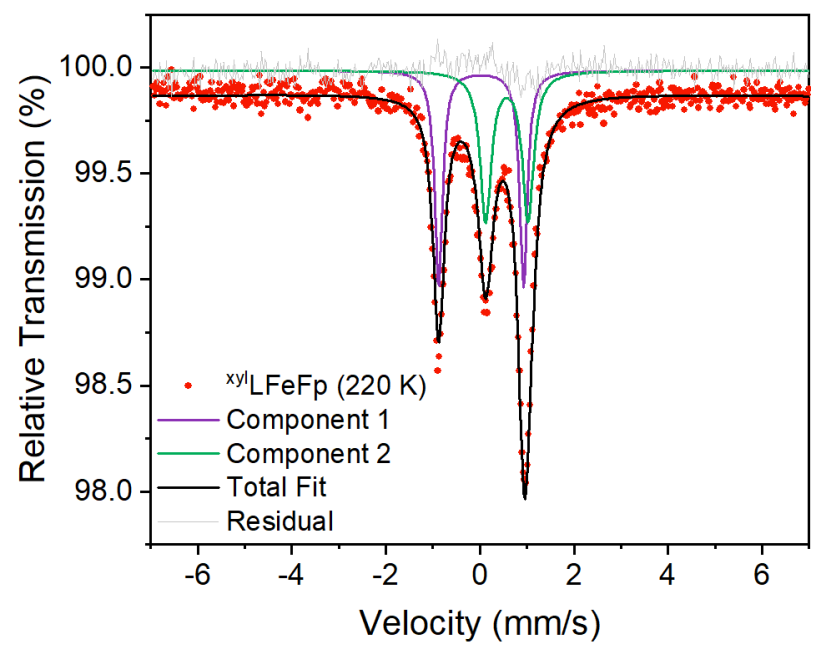

Figure 3. The ${ }^{57}$ Fe Mössbauer spectrum of 1 a at 220 K. Modelled as staggered, for nested fit see S.I.

The ${ }^{57} \mathrm{Fe}$ Mössbauer spectrum of $\mathbf{1 a}$ at $220 \mathrm{~K}$ displays two overlapping doublets having equal intensities. The spectrum can be fit in two ways (nested or staggered doublets), but the two possibilities give parameters that are almost indistinguishable (Table S2). For clarity, only the staggered fit will be discussed here for both 1a and 1b. Modelling the $220 \mathrm{~K}$ Mössbauer spectrum as two staggered doublets led to isomer shift ( $\delta$ ) (and quadrupole splitting, $\left|\Delta E_{\mathrm{Q}}\right|$ ) 
values of $0.03 \mathrm{mms}^{-1}\left(\left|\Delta E_{\mathrm{Q}}\right|=1.80 \mathrm{~mm} \mathrm{~s}^{-1}\right)$ and $0.57 \mathrm{mms}^{-1}\left(\left|\Delta E_{\mathrm{Q}}\right|=0.90 \mathrm{~mm} \mathrm{~s}^{-1}\right)$. The former doublet is similar to those found in $\mathrm{CpFe}^{0}(\mathrm{CO})_{2}$ compounds, such as that in $\mathrm{Ar}^{\prime} \mathrm{Fe}-\mathrm{Fp}\left(\delta_{190 \mathrm{~K}}\right.$ $=0.08 \mathrm{~mm} \mathrm{~s}^{-1},\left|\Delta E_{\mathrm{Q}}\right|=1.73 \mathrm{~mm} \mathrm{~s}^{-1}$ ) and has a smaller shift than $\mathrm{Fe}^{\mathrm{II}}$ compounds with similar coordination environments, such as $\mathrm{CpFe}^{\mathrm{II}}(\mathrm{CO})_{2} \mathrm{Cl}\left(\delta_{220 \mathrm{~K}}=0.14 \mathrm{~mm} \mathrm{~s}^{-1},\left|\Delta E_{\mathrm{Q}}\right|=1.83 \mathrm{~mm} \mathrm{~s}^{-}\right.$ $\left.{ }^{1}\right)$, and smaller than the anion, $\mathrm{K}\left[\mathrm{CpFe}^{0}(\mathrm{CO})_{2}\right]\left(\delta_{80 \mathrm{~K}}=0.16 \mathrm{~mm} \mathrm{~s}^{-1},\left|\Delta E_{\mathrm{Q}}\right|=2.07 \mathrm{~mm} \mathrm{~s}^{-1}\right) .{ }^{[18,22]}$ The other doublet is comparable to values for high-spin three coordinate $\mathrm{L}^{\mathrm{c}} \mathrm{Fe}^{\mathrm{II} X}$ species, for example $\mathrm{L}^{\mathrm{c}} \mathrm{FeCl}\left(\delta_{4.2 \mathrm{~K}}=0.74 \mathrm{~mm} \mathrm{~s}^{-1},\left|\Delta E_{\mathrm{Q}}\right|=1.61 \mathrm{~mm} \mathrm{~s}^{-1}\right)$ and $\mathrm{L}^{\mathrm{c}} \mathrm{FeCH}_{3}\left(\delta_{4.2 \mathrm{~K}}=0.48 \mathrm{~mm} \mathrm{~s}^{-}\right.$ 1, $\left.\left|\Delta E_{\mathrm{Q}}\right|=1.74 \mathrm{~mm} \mathrm{~s}^{-1}\right)\left(\mathrm{L}^{\mathrm{c}}=3,5\right.$-bis(2,6-diisopropylphenylimido)-2,6-dimethylheptyl). ${ }^{[23]}$ These data led to a working model for the complex that assigns the sites as being a low-spin $\mathrm{Fe}^{0}\left(\mathrm{CpFe}(\mathrm{CO})_{2}\right)$ and a high-spin $\mathrm{Fe}^{\mathrm{II}}(\mathrm{LFe})$.

Cooling the Mössbauer sample to $80 \mathrm{~K}$ resulted in broadening of the signal attributed to the $\mathrm{Fe}^{\mathrm{II}}$ site, while the signal associated with $\mathrm{CpFe}(\mathrm{CO})_{2}$ remains almost unchanged. In threecoordinate $\beta$-diketiminatoiron(II) complexes, such broadening upon decreasing temperature is indicative of slow magnetic relaxation caused by the presence of orbital near-degeneracy, and increased spin-orbit coupling. ${ }^{[23]}$ On the other hand, the Mössbauer spectrum of $\mathbf{1 b}$ at $80 \mathrm{~K}$ displayed no evidence of broadening of the doublet attributed to the $\mathrm{Fe}^{\mathrm{II}}$ site. Modelling the 80 $\mathrm{K}$ Mössbauer spectrum of $\mathbf{1 b}$ as a staggered conformation afforded two equal-intensity doublets with fit parameters comparable to those of $1 \mathbf{a}$, with $\delta\left(\left|\Delta E_{\mathrm{Q}}\right|\right)$ of $0.65 \mathrm{~mm} \mathrm{~s}^{-1}\left(\left|\Delta E_{\mathrm{Q}}\right|=\right.$ $\left.0.79 \mathrm{~mm} \mathrm{~s}^{-1}\right)$ and $0.05 \mathrm{mms}^{-1}\left(\left|\Delta E_{\mathrm{Q}}\right|=1.70 \mathrm{~mm} \mathrm{~s}^{-1}\right)$. These are assigned as $\mathrm{L}^{\mathrm{b}} \mathrm{Fe}^{\mathrm{II}}$ and $\mathrm{CpFe}^{0}(\mathrm{CO})_{2}$, as in 1a. 


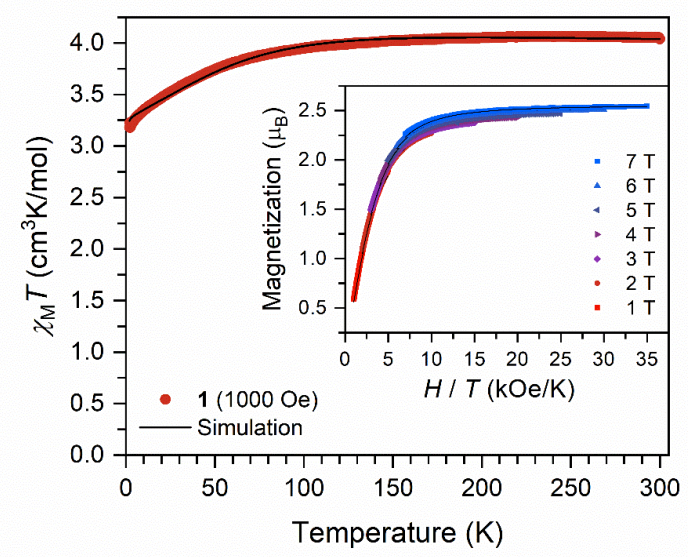

Figure 4. Direct current SQUID magnetometry data for $\mathbf{1 a}$.

We gained deeper insight into the magnetic properties of $\mathbf{1 a}$ and $\mathbf{1 b}$ using SQUID magnetometry. The variable temperature magnetic susceptibility data of 1a were collected under a d.c. magnetic field of 1000 Oe, and they reveal non-Curie law behaviour, consistent with a magnetically anisotropic ground state (Figure 4). The $\chi_{\mathrm{M}} T$ value of $4.05 \mathrm{~cm}^{3} \mathrm{~K} / \mathrm{mol}$ at $300 \mathrm{~K}$ supports an $S=2$ ground state with a $g_{\text {iso }}$ value of 2.32 , consistent with the high-spin iron(II) site assigned by Mössbauer spectroscopy. Below $200 \mathrm{~K}$, the value of $\chi_{\mathrm{M}} T$ decreases with decreasing temperature, reaching a minimum value of $3.18 \mathrm{~cm}^{3} \mathrm{~K} / \mathrm{mol}$ at $2 \mathrm{~K}$. The temperature dependence of $\chi_{\mathrm{M}} T$ indicates the presence of zero-field splitting. To quantitate the magnitude of zero-field splitting in 1a, we fit the variable-field, variable-temperature magnetization data of 1a to the Van Vleck equation using the spin Hamiltonian $\hat{H}=D \hat{S}_{\mathrm{z}}^{2}+$ $E\left[\left(\hat{S}_{\mathrm{x}}{ }^{2}-\hat{\mathrm{S}}_{\mathrm{y}}{ }^{2}\right)+\left(g_{\mid}+g_{\perp}\right) \mu_{\mathrm{B}} \boldsymbol{S} \boldsymbol{H}\right.$. In this Hamiltonian, $D$ and $E$ are the axial and transverse zerofield splitting parameters, $S_{\mathrm{i}}(\mathrm{i}=x, y, z)$ are the spin operators, and $g_{\|}$and $g_{\perp}$ are the parallel and perpendicular $g$-values. Figure 4 shows the best fit to the experimental data that was accomplished with $D$ and $E$ values of $-50 \mathrm{~cm}^{-1}$ and $4 \mathrm{~cm}^{-1}$, respectively, and $g_{\|}$and $g_{\perp}$ values of 2.56 and 2.13, respectively. The analogous treatment of d.c. data for $\mathbf{1 b}$ gave $D$ and $E$ values of $-13 \mathrm{~cm}^{-1}$ and $0 \mathrm{~cm}^{-1}$, respectively. A summary of the spectroscopic and magnetic data for both complexes can be found in Table 1. 
Table 1. Summary of spectroscopic and magnetic data for compounds $\mathbf{1 a}$ and $\mathbf{1 b}$. Mössbauer data collected at $220 \mathrm{~K}$ for $\mathbf{1 a}$ and $80 \mathrm{~K}$ for $\mathbf{1 b}$.

\begin{tabular}{|l|l|l|l|l|l|l|l|}
\hline & $\delta\left(\mathrm{mms}^{-1}\right)$ & $\mid \Delta E_{\mathrm{Q}}\left(\mathrm{mms}^{-1}\right)$ & $\Gamma_{\mathrm{L} / \mathrm{R}}$ & $D\left(\mathrm{~cm}^{-1}\right)$ & $E / D\left(\mathrm{~cm}^{-1}\right)$ & $g_{\perp}, g_{\|}$ & $\begin{array}{l}\chi_{\mathrm{M}} T \\
\left(\mathrm{~cm}^{3} \mathrm{~K} / \mathrm{mol}\right)\end{array}$ \\
\hline $\mathbf{1 a}$ & 0.03 & 1.80 & 0.19 & -50 & 0.08 & 2.13, & 4.06 \\
& 0.57 & 0.90 & 0.28 & & & 2.56 & \\
\hline $\mathbf{1 b}$ & 0.05 & 1.70 & 0.14 & -13 & 0 & 2.16, & 3.43 \\
& 0.65 & 0.79 & 0.15 & & & 2.10 & \\
\hline
\end{tabular}

Density functional theory (DFT) calculations were performed using ORCA 4.0 software. The structures of $\mathbf{1 a}$ and $\mathbf{1 b}$ were optimized at both the B3LYP/ZORA-def2TZVP and BP86/ZORA-def2TZVP level with a $S=2$ ground state. In all cases the optimized structures produced bond parameters in close agreement with the crystal structure data (Table S6). For 1a, the primary difference between the optimized structure and the solid-state structure is the orientation of the $\mathrm{Fp}$ moiety, which rotates $33^{\circ}$ around the $\mathrm{Fe}-\mathrm{Fe}$ axis. As previously noted, the ${ }^{1} \mathrm{H}$ NMR data indicate free rotation about the Fe-Fe bond and so this difference likely arises from a low-energy torsion that is exerted by crystal packing effects. The B3LYP functional more accurately reproduced the Mössbauer isomer shift parameters over BP86 and was used for all further calculations (Table S7). It should be noted that the calculated quadrupole splitting values for the three-coordinate iron site were far from the experimental observations, regardless of method used (e.g. 1a Fe2 $\left|\Delta E_{\mathrm{Q}}\right|=0.90$ (experimental), 2.03 (B3LYP), 1.85 (BP86) $\mathrm{mm} \mathrm{s}^{-1}$ ). Such disagreement between experimental and calculated $\Delta E_{\mathrm{Q}}$ was also reported for $\mathrm{Fe}_{2}(\mathrm{tim})_{2}$, and may reflect an inability of single-determinantal DFT to reproduce electric field gradients that arise from admixed states. ${ }^{[17]}$ With this caveat, we treat the computational models as faithful representations of the electronic structure.

To further understand the metal-metal bonding interaction, intrinsic bonding orbital (IAOIBO) calculations were performed (Figure 5a). The spin-down orbital $54 \beta$ is the principal 
bonding orbital and is best described as a $\sigma$-bonding orbital formed primarily from $\mathrm{Fe} 2 \mathrm{~d}$ orbitals $(78.3 \%)$ with a small contribution from Fe1 (7.8\%). The corresponding spin-up orbital, $61 \alpha$, is also primarily $\mathrm{Fe} 2 \mathrm{~d}$-orbital based (84.7\%), but has a much smaller contribution from Fe1 (3.4\%). The discrepancy in the amount of contribution in the $\alpha$ and $\beta$ orbitals indicates the presence of significant spin polarization.

Analysis of the unrestricted corresponding orbitals (UCOs) shows that the highest-lying doubly occupied orbital and the four singly-occupied orbitals are the $d_{\mathrm{xy}}, d_{\mathrm{z}}^{2}, d_{\mathrm{x}-\mathrm{y}}^{2}$, and $d_{\mathrm{yz}}$ orbitals of high-spin Fe1, respectively (Figure 5b). ${ }^{[23]}$ These appear very similar to the frontier orbitals in other three-coordinate $\beta$-diketiminate complexes that are high-spin iron(II). The only significant contribution from $\mathrm{Fe} 2$ is in the $d_{\mathrm{z}}^{2}$ orbital, which can be described as the $\sigma^{*}$ orbital of the Fe-Fe bond. Since the $\sigma$-orbital is doubly occupied and the $\sigma^{*}$-orbital is singly occupied, the simplest valence-bond picture is of a bond order of 0.5 . The Mayer bond order calculated for the Fe-Fe bond is 0.59 , in agreement with this assessment. So, even though the $\mathrm{Fe}-\mathrm{Fe}$ bond is very short, the covalent interaction between the metals is limited because there is an electron in an antibonding orbital. This implies that there is a significant electrostatic contribution to the bond. Overall, the predominance of $\mathrm{Fe} 2$ in the $\sigma$-bonding orbital and predominance of $\mathrm{Fe} 1$ in the $\sigma^{*}$-bonding orbital strongly support the idea that the $\mathrm{Fe}$-Fe bond is a Lewis base-Lewis acid interaction between a $[\mathrm{Fp}]^{-}$anion to a $[\mathrm{LFe}]^{+}$cation, i.e. $\left[\mathrm{LFe}^{\mathrm{II}}\right]^{+} \leftarrow\left[\mathrm{Fe}^{0}(\mathrm{CO})_{2} \mathrm{Cp}\right]^{-}$. 

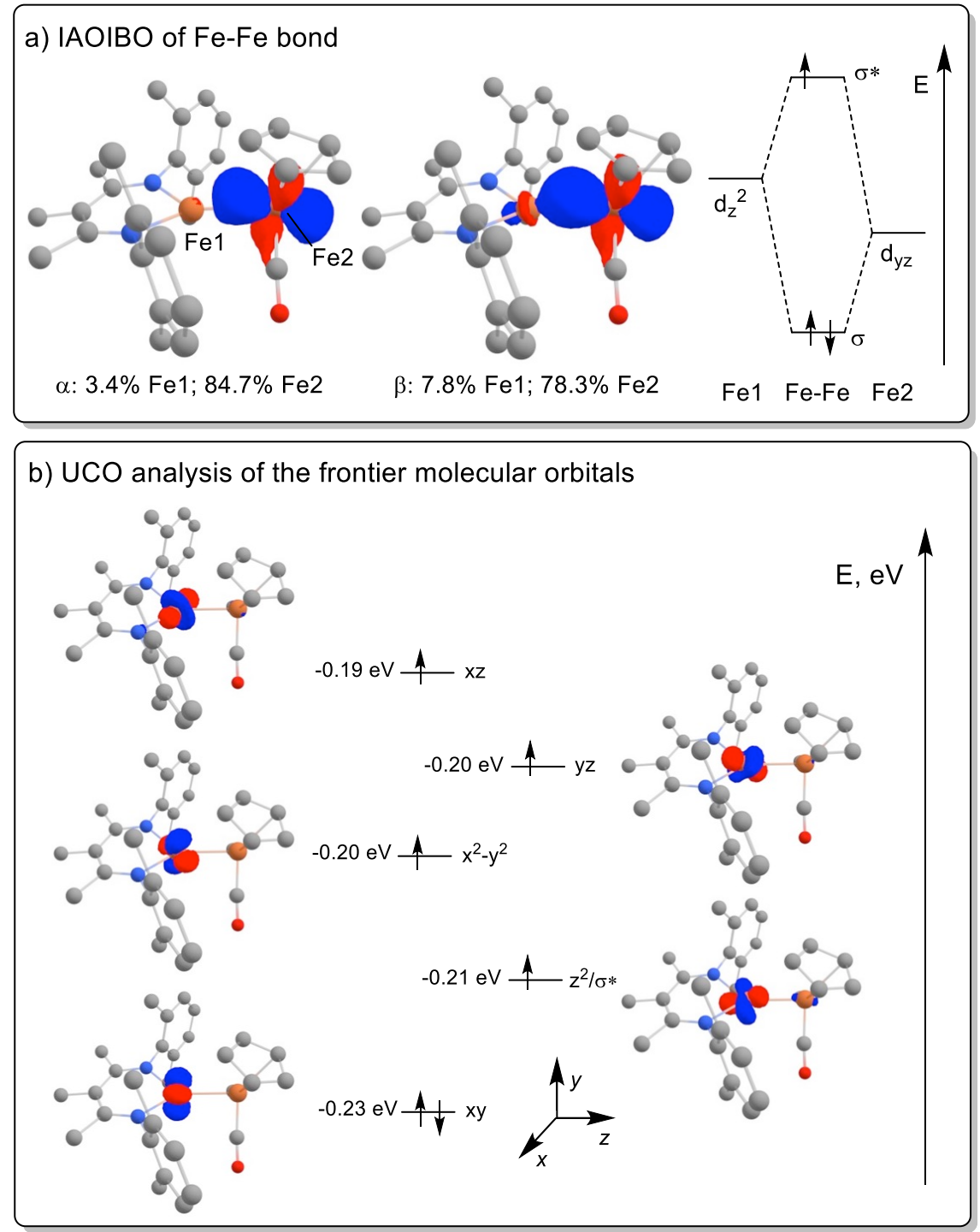

Figure 5. a) IAOIBO analysis of the Fe-Fe bonding interaction in 1a. The right side depicts a simplified Fe-Fe orbital diagram, integrating the findings of the UCO calculation. b) Qualitative molecular orbital diagram for 1 a from the unrestricted corresponding orbitals. Calculations performed using the B3LYP/ZORA-def2TZVP. Isosurface value of 0.05. Hydrogen atoms omitted for clarity. $E=$ Energy.

The availability of LFeR complexes in the literature, in which R can be a variety of ligands, allows us to investigate the classification of $\mathrm{Fp}^{-}$as a ligand. ${ }^{[23-26]} \mathrm{A}$ particularly useful tool is the Mössbauer isomer shift, which gives information about the $s$-orbital electron density at the Fe nucleus. Figure 6 displays a plot of the isomer shift of some known three-coordinate LFe ${ }^{\mathrm{II}} \mathrm{R}$ complexes ( $\mathrm{L}$ is any $\beta$-diketiminate ligand). Softer ligands $\left(\mathrm{CR}_{3}, \mathrm{PR}_{2}\right)$ appear at lower isomer shifts than harder ligands $\left(\mathrm{Cl}, \mathrm{NR}_{2}\right)$. This is further corroborated by the phosphide series, which follows a Hammett relationship $(\mathrm{Cy}>i \mathrm{Pr}>\mathrm{Ph})$, with more strongly donating ligands at lower isomer shifts. On this scale, $\mathrm{Fp}$ falls in the region of phosphides and $\mathrm{CPh}_{3}$ in terms of ligand 
properties. A recent computational study on $\mathrm{Ln}-\mathrm{Fp}$ bonding $(\mathrm{Ln}=$ lanthanide $)$ concluded that Fp is comparable to iodide, $\mathrm{I}^{-} .{ }^{[27]}$ Our results indicate that in this high-spin iron(II) system, Fp ${ }^{-}$ is a stronger donor than $\mathrm{I}^{-}$.

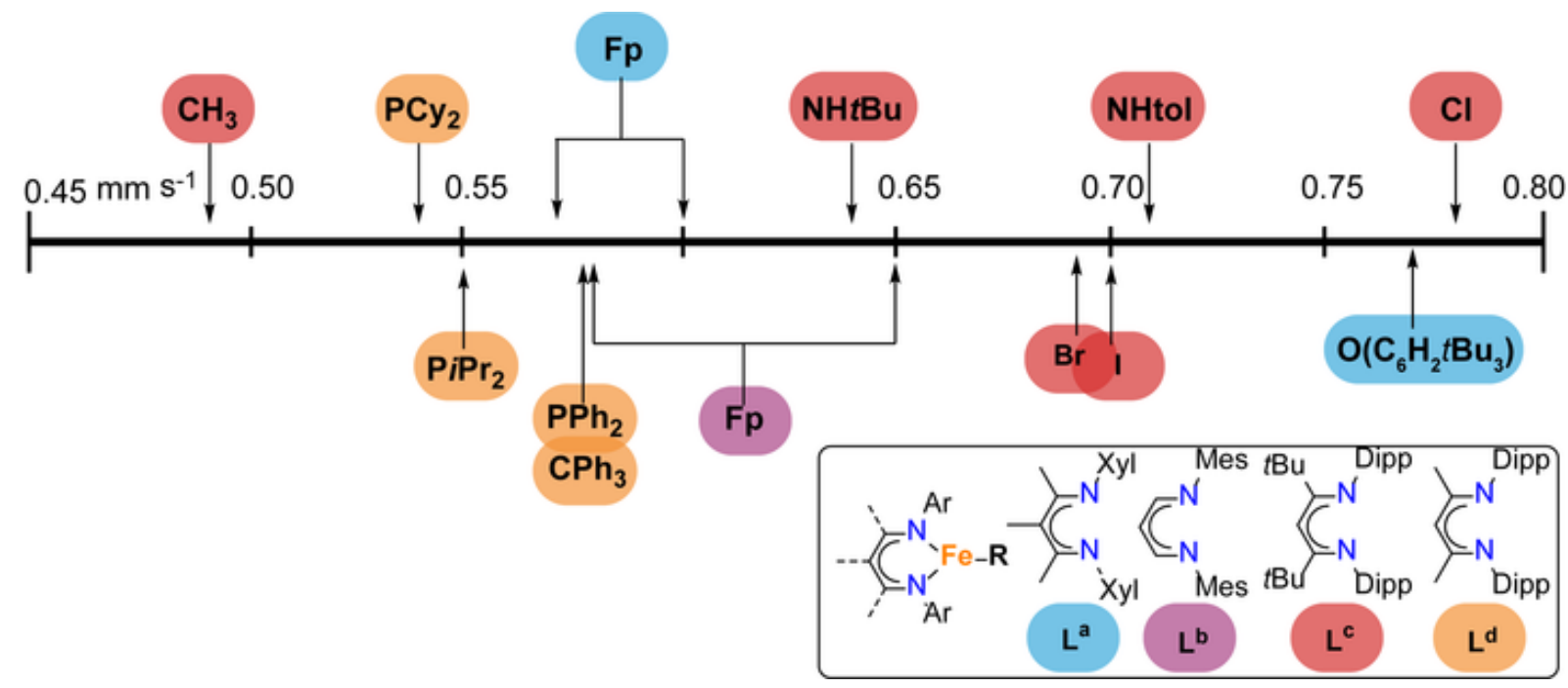

Figure 6. Mössbauer isomer shifts $\left(\delta\left(\mathrm{mm} \mathrm{s} \mathrm{s}^{-1}\right)\right.$ of $L^{x} \mathrm{Fe}^{I I} R$ complexes. $L^{d}=2$,4-bis(2,6-diisopropylphenylimido)pentyl. Experimental details can be found in Table S4. Two isomer shift values for each Fp complex are given due to differing fit parameters.

In conclusion, we have shown an organometallic diiron complex in which an $\mathrm{Fe}-\mathrm{Fe}$ bond connects a high-spin iron(II) site and a low-spin iron(0) site. This may be described as a $\mathrm{CpFe}(\mathrm{CO})_{2}{ }^{-}$fragment acting as an X-type ligand toward the diketiminate-Fe fragment, using the MLX notation of Green. ${ }^{[28]}$ Despite the short Fe-Fe distance $(2.41 \AA)$, the bond order of 0.5 implies limited covalent interaction and significant electrostatic interaction between the metals. Using the accumulated ${ }^{57} \mathrm{Fe}$ Mössbauer database of diketiminate-Fe compounds, the $\mathrm{CpFe}(\mathrm{CO})_{2}$ "metalloligand" can be classified as more donating than halides or $\mathrm{O} / \mathrm{N}$ ligands, but not as soft as most alkyl ligands. In the future, this method could be used to design systems with precisely tuned metalloligands. 


\section{Acknowledgements}

This work was funded by the National Institutes of Health (GM-065313 to P. L. H. and 1F32GM-136179-0181 to M. S. F.). We thank Samuel M. Bhutto for providing a Mössbauer sample. We thank Dr Nicholas Bingham and Prof. Peter Schiffer for magnetometry measurements.

\section{References}

[1] H. Schäfer, H. G. Schnering, Angew. Chem. 1964, 76, 833-849.

[2] B. G. Cooper, J. W. Napoline, C. M. Thomas, Catal. Rev. - Sci. Eng. 2012, 54, 1-40.

[3] J. F. Berry, C. C. Lu, Inorg. Chem. 2017, 56, 7577-7581.

[4] J. Campos, Nat. Rev. Chem. 2020, 4, 696-702.

[5] Multiple Bonds Between Metal Atoms (Eds.: F. A. Cotton, C. A. Murillo, R. A. Walton), 3rd ed., Springer, New York, 2005, pp. 447-451.

[6] F. A. Cotton, Acc. Chem. Res. 1969, 2, 240-247.

[7] H. C. Yu, N. P. Mankad, Synth. 2021, 53, 1409-1422.

[8] R. M. Charles, T. P. Brewster, Coord. Chem. Rev. 2021, 433, 213765.

[9] P. A. Lindahl, J. Inorg. Biochem. 2012, 106, 172-178.

[10] D. Coucouvanis, J. Han, N. Moon, J. Am. Chem. Soc. 2002, 124, 216-224.

[11] R. Bjornsson, F. A. Lima, T. Spatzal, T. Weyhermüller, P. Glatzel, E. Bill, O. Einsle, F. Neese, S. Debeer, Chem. Sci. 2014, 5, 3096-3103.

[12] D. Luart, M. Sellin, P. Laurent, J. Y. Salaün, R. Pichon, L. Toupet, H. des Abbayes, Organometallics 1995, 14, 4989-4991.

[13] T. M. Bockman, H. C. Cho, J. K. Kochi, Organometallics 1995, 14, 5221-5231.

[14] H. B. Chin, M. B. Smith, R. D. Wilson, R. Bau, J. Am. Chem. Soc. 1974, 96, 5285-5287.

[15] L. H. Gade, Angew. Chem. Int. Ed. 2000, 39, 2658-2678.

[16] M. Herberhold, G. -X Jin, Angew. Chem. Int. Ed. 1994, 33, 964-966. 
[17] C. R. Hess, T. Weyhermüller, E. Bill, K. Wieghardt, Angew. Chem. Int. Ed. 2009, 48, $3703-3706$.

[18] H. Lei, J. D. Guo, J. C. Fettinger, S. Nagase, P. P. Power, J. Am. Chem. Soc. 2010, 132, $17399-17401$.

[19] W. W. Brennessel, R. E. Jilek, J. E. Ellis, Angew. Chem. Int. Ed. 2007, 46, 6132-6136.

[20] L. Pauling, J. Am. Chem. Soc. 1947, 69, 542-553.

[21] E. Hey-Hawkins, H. G. von Schnering, Zeitschrift fur Naturforsch. - Sect. B J. Chem. Sci. 1991, 46, 621-624.

[22] M. A. El-Hinnawi, M. A. Kobeissi, Inorganica Chim. Acta 1989, 166, 99-103.

[23] H. Andres, E. L. Bominaar, J. M. Smith, N. A. Eckert, P. L. Holland, E. Münck, J. Am. Chem. Soc. 2002, 124, 3012-3025.

[24] K. Kaniewska, A. Dragulescu-Andrasi, Ł. Ponikiewski, J. Pikies, S. A. Stoian, R. Grubba, Eur. J. Inorg. Chem. 2018, 2018, 4298-4308.

[25] K. C. MacLeod, S. F. McWilliams, B. Q. Mercado, P. L. Holland, Chem. Sci. 2016, 7, $5736-5746$.

[26] K. C. MacLeod, I. M. Dimucci, E. P. Zovinka, S. F. McWilliams, B. Q. Mercado, K. M. Lancaster, P. L. Holland, Organometallics 2019, 38, 4224-4232.

[27] X. Yang, C. P. Burns, M. Nippe, M. B. Hall, Inorg. Chem. 2021, 60, 9394-9401.

[28] M. L. H. Green, J. Organomet. Chem. 1995, 500, 127-148. 
Graphical Abstract:
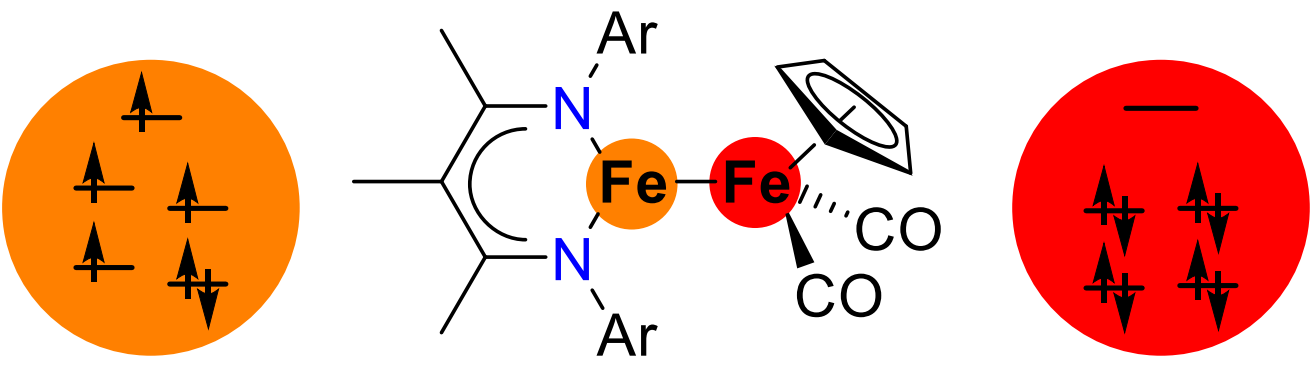